\title{
Current Status of Antiretroviral Therapy (ART) for Acquired Immunodeficiency Syndrome(AIDS) in Bangladesh
}

\author{
HAMN AHASAN ${ }^{\mathrm{a}}$, HT HOSSAIN ${ }^{\mathrm{b}}$, IB REZA $^{\mathrm{c}}$
}

(J Bangladesh Coll Phys Surg 2018; 36: 118-122)

DOI: http://dx.doi.org/10.3329/jbcps.v36i3.37036

Acquired immunodeficiency syndrome (AIDS) caused by the human immunodeficiency virus (HIV) is a threat and can be termed as a curse upon the human race.The physicians and scientists first noticed and recognized thepresence of AIDS as an actual disease following an increase in the incidence of rare opportunistic infections and cancers among otherwise healthy homosexual men ${ }^{1}$.

The first case of an unknown syndrome was repor-ted in USA in 1981, characterized by a profound drop in CD4+ T lymphocyte counts and subsequent immune depression of patients. In those days, the disease was called "Gay pest", "Gay cancer" or Gay-related im-mune deficiency (GRID), due to its major incidence among men having sex with men (MSM) ${ }^{2,3}$.Further demonstration that heterosexual patients were equally susceptible to infection led to its official de-finition as Acquired Immunodeficiency Syndrome (AIDS) ${ }^{4}$.

The etiological agent of AIDS was first identified in 1983, by the French virologist Luc Montagnier and theyidentified retroviral particles and reversetranscriptase activity in cultures of lym-phocytes isolated from AIDS patients. This was the first report

a. Prof. HAM Nazmul Ahasan, Professor, Medicine, Popular Medical College Hospital, Dhaka

b. Dr. Homayra Tahseen Hossain, Associate Professor, Medicine, Popular Medical College Hospital

c. Dr. Ishrat Binte Reza, Registrar, Medicine, Popular Medical College Hospital

Address of Correspondence: Prof. HAM Nazmul Ahasan, Professor, Department of Medicine, Popular Medical College Hospital, Dhaka. E-mail: ahasanhamn@yahoo.com

Received: 16 Feb. 2018

Accepted: 10 May 2018 associating a retrovirus with AIDS, but not conclusive on their causal relationship. Less than a year later, the group led by Robert C. Gallo at the National Cancer Institute provided solid evidences in four reports, supporting the hypothesis of a new retro-virus as the causal agent of AIDS $^{5-9}$. The corner stone in Gallo-s work was to replicate the new virus in a tumor cell line of lymphoid origin (H9), provi-ding enough viral material to characterize its proteins and to develop serologic diagnosis methods to detect antibodies specific for the virus in patient's sera ${ }^{10}$. Consequently, the nucleotide sequences of two diffe-rent but similar viruses were elucidated, markedly different from any previously identified human retro-virus ${ }^{11,12}$. This was the basis for denominating the new entity as the Human Immunodeficiency Virus (HIV) ${ }^{12}$.

\section{Burden in Bangladesh:}

In world,total no of people living with HIV is 36.7 million,20.9 million people is receiving antiretroviral therapy,new infected HIV case is 1.8 million, deaths due to AIDS is 1.0 million. ${ }^{13}$

In Bangladesh the first HIV case was detected in 1989.HIV prevalence remains less than $0.01 \%$ among general population.Estimated people living with HIV is 11,700 .In 2017,total number of new cases were 856. Reported cases for Rohinga crises from $25^{\text {th }}$ August 2017 till now is 168.In 2015,treatment was given among 4665 people living with HIV and in the last year total no of ARV receiver was 2642. ${ }^{13}$

Anti-retroviral therapy past and present: In $<30$ years of antiretroviral therapy (ART), there have been more than 25 drugs developed. In 1987, the first 
antiretroviral agent, zidovudine (AZT), a nucleoside reverse transcriptase inhibitor (NRTI), was shown to have a positive impact on clinical progression and death ${ }^{14}$

The challenges of early NRTI regimens included high pill burdens, inconvenient dosing, treatment-limiting toxicities and incomplete virological suppression. Sequential monotherapy and incomplete virological suppression resulted in the emergence of multiple resistance mutations, with long-term treatment consequences.In treatment of Human immunodeficiency virus (HIV) protease inhibitors (PIs) and non-nucleoside reverse transcriptase inhibitors (NNRTIs), introduced in the mid-1990s, revolutionized the management of HIV infection. Highly active antiretroviral therapy (HAART) regimens, consisting of two NRTIs plus a PI or NNRTI, were capable of virological suppression $(<400$ copies ml"' $)$, and widespread uptake quickly led to dramatic reductions in morbidity and mortality in the developed world ${ }^{15}$. HAART provides effective treatment options for treatment-naive and treatmentexperienced patients.

\section{Common antiretroviral drugs: Drugs are classified into following:}

\section{Reverse Transcriptase Inhibitors}

Reverse transcriptase inhibitors are a group of drugs, which can bind and inhibit the reverse transcriptase enzyme to intercept the multiplication of HIV. There are two types of inhibitors: Non-Nucleoside Reverse Transcriptase Inhibitors (NNRTIs) ${ }^{16}$ and Nucleoside Reverse Transcriptase Inhibitors (NRTI) ${ }^{17}$. Examples of this group of drugs include Zidovudine, Didanosine, Abacavir, Tenofovir, and Combivir.

\section{Protease Inhibitor:}

Regulation of HIV protease is of high importance for the correct assembly and production ofHIV. Protease inhibitors effectively block the functioning of protease enzymes in acutely andchronically HIV-infected CD4 cells. Inhibition of HIV protease enzymes results in the liberationof immature and noninfectious viral particles ${ }^{18}$. Examples of this group of drugs includelopinavir/ritonavir, Indinavir, Ritonavir, Nelfinavir, and Amprenavir.

\section{Fusion Inhibitors :}

This class of drugs acts by blocking HIV from entering the CD4 cells of infected patients. Theyinhibit the fusion of HIV particles with the CD4 cells ${ }^{19}$. Enfuvirtide is an example of a fusion inhibitor used in HIV treatment.

\section{Chemokine Receptor 5 Antagonist}

This group of drugs prevents the infection by blocking the Chemokine Receptor 5 (CCR5)antagonist receptor present on CD4 cells. In the absence of vacant CCR5 receptors, HIV fails to gain entry and infect the cell ${ }^{20}$. Maraviroc is an example of a CCR5 antagonist used in HIV treatment.

\section{Integrase Strand Transfer Inhibitors}

Strand transfer inhibitors prevent the integration of viral DNA into the host genome of CD4 cells by an integrase enzyme. Blocking integrase prevents HIV from replicating ${ }^{21}$. Raltegravir, Elvitegravir, and Dolutegravir are some medications in this category.

ART should be initiated in all individuals with HIV regardless of WHO clinical stage

or CD4 count.Adherence to treatment is of paramount importance in order to achieve the full efficacy of treatment and also to prevent the incidence of drug resistance ${ }^{23}$.

The strategy of using two NRTIs plus a potent third agent still forms the cornerstone of current treatment principles, and is now referred to as combination antiretroviral therapy. According to WHO Guideline there are first, second, and third line treatment options $^{22}$.

\section{First-line ART}

Adults: First-line ART treatment for adults consists of two NRTIs and one NNRTI. Tenofovirdisoproxilfumarate (TDF) + lamivudine (3TC) or Emtricitabine $($ FTC $)+$ Efavirenz $($ EFV) as a fixed dose is the favored choice for this type of ART.

When this drug combination is contraindicated or is unavailable,

1) zidovudine $(\mathrm{AZT})+3 \mathrm{TC}+\mathrm{EFV}$,

2) $\mathrm{AZT}+3 \mathrm{TC}+$ nevirapine (NVP),

or

3) TDF + 3TC (or FTC) + NVP is used.

Pregnant and breastfeeding patients: First-line ART in this subpopulation is comprised of a single daily dose of TDF + 3TC (or FTC) + NVP. Breastfeeding infants 
of mothers who are receiving ART must receive six weeks of infant prophylaxis with a daily dose of NVP. The preventive medication should commence immediately post-delivery or when HIV exposure is identified.

Pediatric patients: Patients below three years of age should be given Lopinavir/Ritonavir(LPV/r)-based treatment, even under NNRTI exposure. When LPV/r is not a viable option, NVP based treatment should be used. For infected children who are over age three, EFV is the ideal NNRTI while NVP has been identified as the second option. For infected children younger than three years of age, who develop TB while on the Lopinavir/Ritonavir (LPV/r)-based treatment, the NRTI regimen should be switched to Abacavir $(\mathrm{ABC})+3 \mathrm{TC}$ or AZT + 3TC until the TB infection is cleared. NRTI regimens similar to that of adults $(\mathrm{TDF}+3 \mathrm{TC}$ (or FTC) $)$ or $(\mathrm{AZT}+3 \mathrm{TC})$ or $(\mathrm{ABC}+3 \mathrm{TC})$ are preferred for patients between 10 and 19 years of age who weight $35 \mathrm{~kg}$ or more.

\section{Second-line ART}

Adults: including pregnant and breastfeeding patients: When a first-line treatment of ART fails, a second-line ART should be utilized. The second-line ART is comprised primarily of two NRTIs and a ritonavirboosted PI. The recommended option for second-line ART includes AZT and 3TC as the NRTI. After the failure of AZT or stavudine (d4T) + 3TC-based firstline regimen, TDF + 3TC (or FTC) as the NRTI should be considered. When first-line NNRTI-based treatment fails, two NRTIs + a boosted PI are suggested.

Pediatric patients: For children below three years of age, first-line ART is continued even whenit fails. No change in treatment is recommended; instead, adequate steps should be taken to improve adherence to the ART regimen. If first-line ART fails in children ages three and up, a second-line treatment consisting of one NNRTI and two NRTIs should be given. If ABC or TDF $+3 \mathrm{TC}$ (or FTC) fails, the recommended option is AZT $+3 \mathrm{TC}$. After a failure of AZT or d4T + 3TC(or FTC) in first-line treatment, the preferred NRTI option is $\mathrm{ABC}$ or TDF + 3TC (or FTC).

\section{Third-line ART}

If first- and second-line ART fails, the WHO recommends inclusion of new medicines with the least amount of risk for development of cross-resistance towards previously used drugs (e.g. integrase inhibitors and second-generation NNRTIs and PIs).

\section{Factors to consider when selecting ART}

The major factors that deserve thorough consideration while choosing an ART for a patient include the viral load and CD4 cell count before the treatment, the result of HIV genotypic drug resistance test, HLA-B*5701 status, patient preferences, and anticipated adherence. Comorbid conditions to screen prior to ART include cardiovascular disease, hyperlipidemia, renal disease,osteoporosis, psychiatric illness, neurologic disease, drug abuse or dependency requiring narcotic replacement therapy, pregnancy, coinfections with hepatitis C (HCV), hepatitis B (HBV), and tuberculosis $(\mathrm{TB})^{24}$.

\section{Contraindications should also be considered:}

1. Creatinine clearance is less than $50 \mathrm{ml}$ per minute: Tenofovir.

2. Patients on psychoactive drug treatment: Efavirenz.

3. Patients who are pregnant or who are trying to conceive: Efavirenz.

4. ALT elevation: Nevirapine.

CD4 count monitoring for therapeutic response Monitoring patients' viral load is critical to identify ART response. When the viral load analysis is not practical via polymerase chain reaction (PCR), branched chained DNA (bDNA), and nucleic acid sequence-based amplification (NASBA), the CD4 count is used as an indicator of HIV treatment response. During the first year of treatment, increases in CD4 count from 50 to 150 cells $/ \mathrm{mm} 3$ with an increased response in the first trimester are considered as a positive response. CD4 count rises steadily ranging from 50 to 100 cells $/ \mathrm{mm} 3$ per year until equilibrium is reached in the subsequent years (normal range: 500 cells/mm3 to 1200 cells $/ \mathrm{mm} 3)^{25}$. Periodic monitoring of CD4 count is required during and even after the patient achieves normal CD4 count under ART.

A number of treatment independent factors like age, viral load, genetic make-up, lifestyle, quality of health care, etc., negatively influence the CD4 counts and HIV disease progression. Under such circumstances, a change in ART medication might be required. 


\section{Treatment available in Bangladesh:}

In Bangladesh first case of HIV was diagnosed 1989. Since then upto 2011 treatment facility for the patient living with HIV depended mostly on the international NGO.From 2012 Bangladesh Government supplying drug through " AIDS/STD program" in collaboration with NGOs . This improved health care service to the patients. From the $1^{\text {st }}$ October 2017,Bangladesh government start ART centre in 6 institutes.They are BSMMU,IDH,Sylhet M.A.G Osmani Medical College Hospital, Chittagong medical college hospital,Khulna medical college hospital,Cox's bazar sador hospital ${ }^{13}$.

In Bangladesh 2 pharmaceutical (Beximco and Square) company producing 6 different types of drugs(abacavir + lamivudine + zidovudine, efavirenz, lamivudine + zidovudine, lamivudine + zidovudine + nevirapine, Nelfinavir).

The specific objectives of an ART centre are to:1) provide Care, Support and Treatment services to all PLHIV and monitor patients in HIV care (Pre- ART) regularly 2) Identify eligible PLHIV requiring ART and initiate them on ART in a timely mal ART guidelines 3) Provide ARV \& OIs drugs to eligible PLHIV 4) Provide treatment adherence and counselling services before and during treatment to ensure high levels of drug adherence 5) Counsel and educate PLHIV, care givers, guardians and family members on nutritional requirements, hygiene, positive living and also on measures to prevent further transmission of infection 6) Refer patients requiring specialized services (including admission) to other departments or higher facilities 7) Provide comprehensive package of services including condoms and prevention education with a view towards "Positive Prevention" 8) Ultimately integrating HIV care into general health system for long term sustainability. ${ }^{26}$.

The regimen that are available in ART centre are:

1. Tab.Lamivodine(3TC)150mg+Zidovudine (AZT) $300 \mathrm{mg}+$ Nevirepine(NVP) 200mg

2. Tab Zidovudine (AZT) 300mg+Lamivudine (3TC) $150 \mathrm{mg}$

3. Tab Efavirenz (EFV) $600 \mathrm{mg}$

4. Tab Lamivodine (3TC) $300 \mathrm{mg}$

5. Tab Tenofovir (TDF) $300 \mathrm{mg}$
6. Tab Lopinavir/Ritonovir(LPV/r) 200mg/50mg

7. Tab Tenofovir 300mg+Emitricitabine 200mg+ Efavirenz $600 \mathrm{mg}$

8. Tab Atanavir /Ritonavir $300 \mathrm{mg}+100 \mathrm{mg}$

9. Tab Tenofovir 300mg +Emtricitabine 200mg

10. Tab Abacavir $300 \mathrm{mg}$

11. Tab Lamivodine (3TC) $30 \mathrm{mg}+$ zidovudine (AZT) $60 \mathrm{mg}+$ Nevirepine (NVP) $50 \mathrm{mg}$

12. Tab Lamivodine (3TC) $30 \mathrm{mg}$ +zidovudine (AZT) $60 \mathrm{mg}$

13. Tab Abacavir 60mg + Lamivodine (3TC) 30mg

14. SypNevirepine $50 \mathrm{mg} / 5 \mathrm{ml}, 100 \mathrm{ml}$

15. SypLopinavire $80 \mathrm{mg} /$ Ritonovire oral Solution, $20 \mathrm{mg} / \mathrm{ml}(160 \mathrm{ml})$

\section{Target to end AIDS epidemic:}

UNAIDS has made an ambitious target treatment to end AIDS epidemic by the year 2030.They set target 90-90-90. By 2020, 90\% of all people living with HIV will know their HIV status. By 2020, $90 \%$ of all people with diagnosed HIV infection will receive sustained antiretroviral therapy. .By $2020,90 \%$ of all people receiving antiretroviral therapy will have viral suppression. This target is also for Bangladesh ${ }^{13}$.

\section{Conclusion:}

People living with HIV in Bangladesh are getting antiretroviral drugs and all facilities are available for diagnosing,treating and monitoring treatment. Previously it was supplied through NGOs. Drugs are now available in different govt. hospital under HIV/ STD control program of DGHS.By ensuring investment \& commitment,increasing the HIV testing facility in different government settings, addressing the epidemic in adolescents and children,comprehensive HIV response to Migrant people,Addressing legal and social barriers we can overcome the challenges.

\section{References :}

1. Friedman-Kien A, Laubenstein L, Marmor M, Hymes K, Green J, Ragaz A, Gottleib J, MuggiaF,Demopoulos R, Weintraub M: Kaposi's sarcoma and Pneumocystis pneumonia among homosexual men —New York City and California. MMWR Morb Mortal Wkly Rep. 1981, 30:305-308.

2. Centers for Disease C. A cluster of Ka-posi's sarcoma and Pneumocystis carinii pneumonia among homosexual male 
resi-dents of Los Angeles and Orange Counties, California. MMWR Morb Mortal Wkly Rep. 1982;31(23):305-7.

3. Gottlieb MS. Pneumocystis pneumo-nia—Los Angeles. 1981. Am J Public Health. 2006;96(6):980-1.

4. Quagliarello V. The Acquired Immuno-deficiency Syndrome: current status. Yale J Biol Med. 1982;55(5-6):443-52.

5. Barre-Sinoussi F, Chermann JC, Rey F, Nugeyre MT, Chamaret $\mathrm{S}$, Gruest $\mathrm{J}$, et al. Isolation of a T-lymphotropic retrovirus from a patient at risk for acquired immune deficiency syndrome (AIDS). Science. 1983;220(4599):868-71.

6. Schupbach J, Popovic M, Gilden RV, Gonda MA, Sarngadharan MG, Gallo RC. Serological analysis of a subgroup of human Tlymphotropic retroviruses (HTLV-III) associated with AIDS. Science. 1984;224(4648):503-5.

7. Popovic M, Sarngadharan MG, Read E, Gallo RC. Detection, isolation, and contin-uous production of cytopathic retroviruses (HTLV-III) from patients with AIDS and pre- AIDS. Science. 1984;224(4648):497-500.

8. Sarngadharan MG, Popovic M, Bruch L, Schupbach J, Gallo RC. Antibodies reactive with human T-lymphotropic retroviruses (HTLV-III) in the serum of patients with AIDS. Science. 1984;224(4648):506-8.

9. Gallo RC, Salahuddin SZ, Popovic M, Shearer GM, Kaplan M, Haynes BF, et al. Frequent detection and isolation of cyto-pathic retroviruses (HTLV-III) from patients with AIDS and at risk for AIDS. Science. 1984;224 (4648):500-3.

10. Weiss SH, Goedert JJ, Sarngadharan MG, Bodner AJ, Group ASCW, Gallo RC, et al. Screening test for HTLV-III (AIDS agent) antibodies: specificity, sensitivity, and applications. JAMA. 2014; 312(4):442.

11. Brass AL, Dykxhoorn DM, Benita Y, Yan N, Engelman A, Xavier RJ, Lieberman J, ElledgeSJ:Identification of host proteins required for HIV infection through a functional genomic screen. Science. 2008, 319:921-26.

12. Fischl MA, Richman DD, Grieco MH, Gottlieb MS, Volberding PA, Laskin OL, Leedom JM, Groopman JE, Mildvan D, Schooley RT, Jackson G, Durack D, King D, the AZT Collaborative Working Group. The efficacy of azidothymidine (AZT) in the treatment of patients with AIDS and AIDS-related complex. A double-blind, placebo-controlled trial. N Engl J Med 1987; 317 : 185-91.

13. National AIDS/STD Program. Bangladesh country situation and national response of HIV/AIDS. Workshop proceedings of coordination \& monitoring of HIV/AIDS programme in priority district.Director General Health Sector. Dhaka: March 20, 2018.

14. Fischl MA, Richman DD, Grieco MH, Gottlieb MS, Volberding PA, Laskin OL, Leedom JM, Groopman JE, Mildvan D, Schooley RT, Jackson G, Durack D, King D, the AZT Collaborative
Working Group. The efficacy of azidothymidine (AZT) in the treatment of patients with AIDS and AIDS-related complex. A double-blind, placebo-controlled trial. N Engl J Med 1987; 317 : $185-91$.

15. Palella FJ Jr, Delaney KM, Moorman AC, Loveless MO, Fuhrer J, Satten GA, Aschman DJ, Holmberg SD. Declining morbidity and mortality among patients with advanced human immunodeficiency virus infection. HIV Outpatient

16. deBéthune MP: Non-nucleoside reverse transcriptase inhibitors (NNRTIs), their discovery,development, and use in the treatment of HIV-1 infection: a review of the last 20 years (1989-2009). Antiviral Res. 2010, 85:75-90.

17. 17.Whitcomb JM, Parkin NT, Chappey C, Hellmann NS, Petropoulos CJ: Broad nucleoside reverse-transcriptase inhibitor cross-resistance in human immunodeficiency virus type 1 clinical isolates. J Infect Dis. 2003, 188:992-1000.

18. 18. Hughes PJ, Cretton-Scott E, Teague A, Wensel TM: Protease inhibitors for patients with HIV-1 infection: A comparative overview. PT. 2011, 36:332-45.

19. 19. Greenberg ML, Cammack N: Resistance to enfuvirtide, the first HIV fusion inhibitor . J AntimicrobChemother. 2004, 54: 333-40.

20. 20. Rao PKS: CCR5 inhibitors: Emerging promising HIV therapeutic strategy . Indian J Sex Transm Dis. 2009, 30:1-9.

21. 21. Pandey KK, Grandgenett DP: HIV-1 Integrase strand transfer inhibitors: Novel insights into their mechanism of action. Retrovirology (Auckl). 2008, 2:11-16.

22. WHO:Guideline on when to start antiretroviral therapy and on pre-exposure prophylaxis for HIV. (2015). Accessed: December 28, 2015:http:/www.who.int/hiv/pub/guidelines/earlyreleasearv/en/.

23. Olem D, Sharp KM, Taylor JM, Johnson MO: Overcoming barriers to HIV treatment adherence:A brief cognitive behavioral intervention for HIV-positive adults on antiretroviral treatment.CognBehavPract. 2014, 21:206-23.

24. AIDS Info: Clinical guidelines Portal. Guidelines for the use of antiretroviral agents in HIV-1-infected adults and adolescents. (2015). Accessed: December 6, 2015:http://aidsinfo.nih.gov/ guidelines.

25. 25. Kaufmann GR, Perrin L, Pantaleo G, Opravil M, Furrer H, Telenti A, Hirschel B, LedergerberB, Vernazza P, Bernasconi E, Rickenbach M, Egger M, Battegay M; Swiss HIV Cohort Study Group: CD4 T-lymphocyte recovery in individuals with advanced HIV-1 infection receiving potent antiretroviral therapy for 4 years: the Swiss HIV Cohort Study. Arch Intern Med. 2003,163: 2187-95.

26. National AIDS/STD Program. Right to health. Dhaka: Director General and Health Sector; 2017: 5-7. 